\title{
Construction of Quality Monitoring System in Postgraduate Education
}

\author{
Huang Deling* \\ College of Software Engineering \\ Chonqing University of Posts and Telecommunication \\ Chongqing 400065, China \\ huangdl@cqupt.edu.cn
}

\author{
Xia Shufang \\ College of Software Engineering \\ Chonqing University of Posts and Telecommunication \\ Chongqing 400065, China \\ xiasf@cqupt.edu.cn
}

\author{
Xu Guangxia \\ College of Software Engineering \\ Chonqing University of Posts and Telecommunication \\ Chongqing 400065, China \\ xugx@cqupt.edu.cn
}

\begin{abstract}
Education quality is the soul of postgraduate education. A good quality monitoring system is the guarantee of improving the education quality. We investigated the current situation of the existing quality monitoring systems. We proposed a quality monitoring system, which employs tutor team mode to overcome the limitation of postgraduates' quality caused by single tutor mode. We also designed the system as an infomatization platform, which can make good use of the network infrastructure and big data to guarantee the reliability and freshness of the quality monitoring system. We have deployed the system in our university, and it has contributed to improve the postgraduates' education quality. We also provide some suggestions of future development of the quality information monitoring system.
\end{abstract}

Keywords-Quality monitoring system, Informatization, Tutor team, Postgraduate

\section{INTRODUCTION}

Education quality is the soul and the lifeline of postgraduate education. Good quality assurance system is the guarantee of improving the training quality of postgraduate students [1]. The quality monitoring system of postgraduate education can supervise, regulate, control, guide and inspire the postgraduates, thus ensure the postgraduates' quality [2]. It is an inevitable requirement for socialism modern economic development. The rapid development of economic society needs high-level professionals with high qualities, under quality monitoring system. Meanwhile, construction the quality monitoring system is also the important mission of the innovation and development in national high education. It will push education quality monitoring into a brand new stage, and match the international development of high education.

At present, our government has formulated laws and regulations, and set up teaching quality monitoring institution. Any academic falsification will be punished under these rules. Meanwhile, our society monitors the postgraduates' quality through intermediary evaluation, employer estimate, patriarchal feedback and media report. As for institution of higher education, many rules, regulations and institutions have been set up to monitor the education quality of postgraduates. However the training quality of postgraduates has shown a worrying status under the single tutor system these years [3] and we've found some problems with the existing quality monitoring system.

First, there is a deviation in monitoring targets. Practical activities play an important part in postgraduate education. Most monitoring systems have not provided the information about practical activities. This is mostly because of that the practical activities always take place outside the campus. Postgraduates are always sent to carry out their practical activities in kinds of enterprises, companies or organizations being a lack in communication with the university. There is usually only one or two times of contact between them. So the state of practical activities, how and when they take places, can't be got in time now without information system. Always, the practical activities can't be guaranteed [4].

Second, the monitoring time and space are out of balance. Most monitoring action are focus on the campus, nevertheless postgraduate's behavior out of campus are equally important. It is a significant factor for shaping a student's behavior, which in-depth shaping one's education quality. On the other hand, most systems focus on the campus life; seldom pay attention to the initial stage of career, which also indicate the postgraduate's quality.

At last, the feedback mechanism isn't completed. The student's tutor, other tutors inside campus, tutors outside campus, students' parents, students' employee and the media, et al., can give some feedback about our postgraduates. There is a lack of a useable channel for all the feedbacks through the system. 
In order to overcome the above mentioned problems, we devote our research to conduct a quality monitoring informatization system for postgraduate training, which employ tutor team mode.

\section{RESEARCH BASIS}

\section{A. Tutor team}

The number of enrolling new students has greatly increased these years. The limitations caused by single tutor system have largely limited the education quality.[5] Hence, there is an impersonal requirement of tutor teams for improving postgraduate's quality nowadays. Our university inspires and implements tutor team training mode, and has a good basis of tutor team mode.

It is highly recommended to do scientific researches under team mode in our university. All the schools which train postgraduates organized their scientific research teams. These teams rely on research laboratories or technology centers, which consist of researchers with similar research areas. The researchers gather and work together as they wish. These wellworked teams provide a strong basis of tutor team mode.

\section{B. Informatization}

Informatization is important for the quality monitoring system, which has been described in section 1 . If feedback and other quality related information cannot be effective integrated, we cannot monitor the education quality effectively. It's not allowable for the existence of isolated information island. Our university has a good informatization situation.

It is forced in our university to use postgraduate training informatization system. This system provides access to the enrollment, daily management, course selections, academic training and tutor management and other aspects of postgraduates training. So it's available and convenient to manage and monitor the above mentioned aspects through informatization method. Moreover, this system has open interfaces, which allow users to add other modules with required function. The bone of computer network in our university has a large bandwidth of 10G bps. All the campus was covered by wire or wireless computer network which provide fast internet connection though both IPv4 of IPv6. In addition, Cloud Computing and Service Research Platform and some other platforms are well-worked in our university. These platforms provide a strong professional practical platform integrates Cloud and Terminal for the postgraduates. The convenient and strong computer network infrastructure of the university provides a solid basis of the informatization of our quality monitoring system.

\section{DEPLOY THE PROPOSED SYSTEM}

\section{A. Basic principle}

1) Including Practical Activities.

The monitoring on practical activities must be strengthened. The practical teaching should match the new developing requirement of the modern society and enterprises. And it should be kept update in time. Meanwhile its monitoring should be combined with academic dissertation. The monitoring should contain research area choice and the research contents, consequently can ensure the close relationship between academic dissertation and practical activities, and also ensure the realistic significance.

\section{2) System Integration.}

The quality monitoring system has some sub-systems. For example, some are responsible for process management, some are responsible for quality evaluation, and some are responsible for feedbacks. These sub-systems should be integrated together, intercoordinate with each other, constitute an efficient entity. Only when they integrated together, can maximize and optimize the function of the system. We should take full consideration about the relationships between each sub-system, control the factors affect the education quality effectively, make sure all the sub-systems and factors keep close contact to be an entity. We should associate all the participants, assure the consistency of all the monitoring objects, and integrate all the monitoring activities.

\section{3) Sharing Responsibility.}

Different participants in the quality monitoring system should take their own responsibility with the same purpose of improving the education quality. Government should take the leading role, which megascopically regulates and controls the quality. It makes the relative policy, evaluates the running state of quality monitoring systems, and affords the education foundation and releases evaluated reports at a fixed period...The universities should construct its own quality assurance system, do self-evaluation periodically, and complete the quality monitoring system constantly. The society monitors the quality through some evaluation organizations. It acts as a monitoring platform, which coordinates all the participants' communication and cooperation. And the students themselves are the subject. They should be responsible for themselves, study hard, and practice innovation. It's the basis of improving education quality.

\section{4) Improving continuously.}

Improvement can keep an entity's vitality, efficiency and competitiveness. The aim of quality monitoring system is to improve the education quality. So we should make every effort to discover the disadvantages, thus improve and complete the running system, make it more effective. While the society is improving, the system needs to be updated frequently to adapt to the environment. These updates cover from the functions and structures of the system, and consequently the training plan of the postgraduates. There must be some way to get feedbacks, which helps to evaluate the system and consequently helps to improve the system.

\section{B. Architecture design}

The postgraduate training is under the guide of university and secondary schools. These years, supported by scientific research groups, tutor team mode of postgraduate education is inspired and has already been implemented. The tutor team consists of researchers with similar research areas. The researchers gather together as they wish. They present as research laboratories or technical centers. Researchers cooperate with each other to supervise the postgraduates, 
through various methods of accesses. Their cooperation covers from enrollment, daily management, academic training and other aspects of postgraduates. In our university, there are three main parallel sub systems of the quality monitoring system, as is shown in Fig. 1.

The Feedback Sub-System adopts bidirectional feedback. On one hand, quality management department bring the suggestion feedback to the feedback rectify and reform department. On the other hand, the feedback rectify and reform department reports back the rectify status to the quality management department. It is a closed loop. It can avoid the feedback missing somewhere in the system.

\begin{tabular}{|l|l|}
\hline \multicolumn{2}{l}{ Process Management System } \\
\hline Enrollment & Research Choice and Proposal \\
\hline Major Training Schedule & Subject Research \\
\hline Personal Training Schedule & Practical Activity \\
\hline Course management & Academic Dissertation \\
\hline Literature Review & Graduation Oral Examination \\
\hline $\begin{array}{l}\text { Tutor Teams Working Quality } \\
\text { Course Quality }\end{array}$ & \multicolumn{1}{|c}{ Feedback System } \\
\hline $\begin{array}{l}\text { Teaching Materials Quality } \\
\text { Postgraduates’ Learning Quality }\end{array}$ & Peer Review Feedback \\
\hline $\begin{array}{l}\text { Postgraduates’ Researching Quality } \\
\text { Dissertation and Oral Examination Quality }\end{array}$ & Supervisors and Inspectors' Feedback \\
\hline
\end{tabular}

Fig. 1. Three main parallel sub systems of the quality monitoring syste

\section{Constructing the monitoring system}

1) Enroll students and distribute tutors on the basis of tutor team, monitor the postgraduates' basic quality.

Under single tutor mode, student who has met the basic requirements of the university will deliver his wish to a certain tutor, then waiting for his offer. This workflow always results in a large number of students come to nothing. Because of no synthetically consideration and distribution of the tutoring resources, many students with good basic quality fail to be accepted under this mode. Tutor team mode can greatly avoid this kind of failure. Under tutor team's mode, the students will deliver their wishes to a tutor team, i.e., a certain research area, rather than a certain tutor. After the enrollments, they are assigned to some tutors according to the specific situation of the team. Moreover, they can change tutors during the training course, if it is necessary. Tutor team's monitoring can protect the students' basic quality.

2) Carry out the social activities, social practice, careers guidance management and the scholarship and grants affair, relying on tutor team, monitor the postgraduates' comprehensive quality.

In the past, postgraduates' daily education management adopted the centralization management under the secondary school. This mode will put a constraint to the postgraduates' improvement while benefit the secondary schools' control [6]. Different from undergraduate, postgraduate has more autonomy on time management, which results in some exceptional case in centralization. Thus we switch centralization to tutor team mode to overcome this shortcoming. Social activities, practice and other research activities, guided by tutor team, can provide more flexibility and pertinence.
3) Implement course development, research choice and proposal, and academic dissertation, relying on tutor team, monitor the academic training quality.

Tutor team being responsible for the course development can keep courses' advancement in a research area. Tutor team contributes to the course complement and innovation. As for the academic dissertation, adopting tutor team avoids problem being exposed till paper review stage or Graduation Oral Examination. Tutor team guides postgraduates from dissertation writing to medium-term inspection, and to graduation oral examination. The evaluating standard and rules are discussed by the team every stage, which provide strongly support to the quality.

4) Build alumni information database, provide continuously monitoring.

Alumni step into the society. Where do they go? What do they do? How is their work? We should collect the information from the graduates at least the first three years after they leave the university. This information helps us to self-evaluate our education quality, and to get the society's evaluation about our postgraduate. We can check if our students match the initial objective we set. During the training process we constantly make comparisons using the objective as a standard, and then try to match the standard by any means. This information helps us to renew the training plan, which determines the training quality. Meanwhile the alumni database will help us make full use of the informatization platform, communicate with the alumni, and acquire more comprehensive resources.

\section{CONCLUSION}

A good quality monitoring system is the guarantee of improving the training quality of postgraduate students. We proposed a quality monitoring system, which employs tutor 
team mode to monitor the education quality, and overcome the single tutor mode. We also design the system as a well infomatization platform, which can make good use of the network infrastructure and big data to apply the reliability and freshness.

\section{ACKNOWLEDGEMENT}

This research was financially supported by Program for Postgraduate Education and Teaching Reform in Chongqing (NO.yjg131008, NO.yjg153028), Education and Teaching Reform Program in Chonqing University of Posts and Telecommunications (NO.XJG1428).

\section{REFERENCES}

[1] S Hasnan,RA Aziz,AA Hamid, Postgraduate Tracking System: Student Research Progress Tracking Tool, International Research in Education, Vol. 3, pp. 47-53, 2015.

[2] D Houston, Quality in postgraduate research, Quality in Higher Education, vol.21, pp. 1-6, 2015.

[3] Deling Huang, Shufang Xia, Construction of the Tutor Team in Postgraduate Education, Advances in Social Science, Education and Humanities Research, vol.37, pp. 1654-1657, 2015.

[4] Ismail, A., Zainal Abiddin, N., Hassan, R., \& Ro's, I, The Profound of Students' Supervision Practice in Higher Education to Enhance Student Development, Higher Education Studies, vol. 4, pp. 1-6, 2014.

[5] LI Ya-Lin, ZHOU Chun-Yang, Strengthening Graduates Tutor Teams Construction to Guarantee Quality of Postgraduate Education, Pharmaceutical Education, vol. 28, pp. 19-23, 2012.

[6] Zainal Abiddin, N., \& Ismail, A, Attrition and Completion Issues in Postgraduate Studies for Student Development, International Review of Social Sciences and Humanities, vol. 1, pp. 15-29, 2011. 